\title{
AEROSOL CHARACTERIZATION FROM ACTIVE AND PASSIVE GROUND MEASUREMENTS AND SATELLITE DATA
}

\author{
Dandocsi Alexandru ${ }^{1,2}$, Sapartoc Georgiana ${ }^{2}$, Preda Liliana ${ }^{2}$, Stan Cristina $^{2}$, Radu Cristian $^{1}$ \\ ${ }^{I}$ National Institute of $R \& D$ for Optoelectronics, Romania, *alexandru.dandocsi@inoe.ro \\ ${ }^{2}$ University Politehnica of Bucharest, Romania
}

\begin{abstract}
One year records of AErosolROboticNEtwork (AERONET) sun photometer measurements were analyzed to investigate the seasonal and daily variations of columnar aerosol optical depth. Some irregularities of this time series are associated with aerosol intrusions. The aerosol layers indicated by these irregularities are identified and characterized using the extensive optical data from coincident CALIPSO satellite observations and ground based LIDAR.
\end{abstract}

\section{INTRODUCTION}

Long term Aerosol Optical Depth studies show interesting influences of natural and anthropogenic aerosol sources. Studies shows daily frequencies as well as weekly or seasonal [1] as well as natural influences like diurnal cycle of the planetary boundary layer (PBL).

Location of the site is in Magurele, a suburban area of Bucharest (26.029E; 44.048N, 93m above sea level). In such location, one can expect to find the urban influence as well as the natural influences of continental climate.

In this study, we use time series analysis to determine the time periods specific to our location and identify some irregularities of the measured AOD values. These irregularities can be explained with the presence of clouds and/or long range transported aerosol layers.

One year record of level 1.5 AOD data from AERONET were used in this analysis and validate the results with level 2 lidar data from Calipso and measurements from a ground based Lidar. Both sun photometer and the ground based Lidar are collocated while the satellite measurements were selected around a $50 \mathrm{~km}$ region around the site.

\section{METHODOLOGY}

One year measurements of the AOD from CIMEL's sun photometer were used in this study, during 2014. The AOD retrieval is computed based on the Beer-Lambert-Bouger equation [2].

The data is measured at various time stamps because of the weather conditions and has missing values. To apply the decomposition algorithm, which gives the frequencies in the AOD data, the time series has to be continuous. In order to identify the small periods and to reduce the error in the same time, we used a sampling rate of 1 for each 12 hours, by averaging the measurements done in first and last 12 hours for each day. Summer time is the most suitable period in terms of AOD because only a specific range of isolated data are missing and it can be easily interpolated using a shape-preserving piecewise cubic interpolation without changing the time evolution. The data shows an almost linear trend probably due to shorter frequencies which can be associated with seasonal variations. Applying the detrend, we estimated a power spectrum density which gives the frequencies of the series.

Removing the frequencies caused by the natural and the anthropogenic influences of the atmosphere, we obtained the irregularities in the AOD measurements. These irregularities can be explained with the presence of long range transported aerosols and/or clouds. To validate this statement we used satellite lidar data and ground based lidar measurement for the given location.

Backscatter and extinction profiles from a multiwavelength Lidar measurements, described by [3], were used to highlight the presence of aerosol layers or clouds and to compare with the measurements from Calipso. Both Lidar and Calipso measurements were used to validate the presence of the irregularities in the AOD data. Calculation of the profiles was made with a good 
accuracy using an assumed lidar ratio and a calibration in the far range [4],[5].

Range corrected signals were used to show an overview of the atmosphere while backscattered profiles were used to indicate the presence of aerosols, using the gradient method described by [6].

From the satellite data point of view, profiles from Lidar data from Level 2, were used. Selection of the profiles was made with a location constraint, only data within $50 \mathrm{~km}$ range from the fixed location were considered.

\section{RESULTS}

One year measurements of the AOD, $500 \mathrm{~nm}$ filter, aerosol related from the sun photometer is shown in Figure 1.Sun photometer measurements for the AOD have a maximum 5\% error [7].

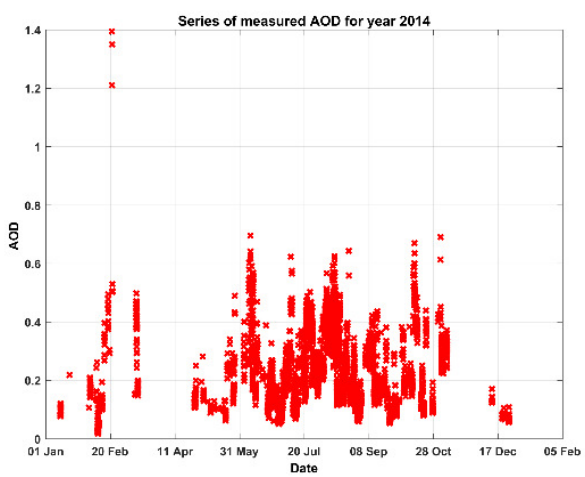

Figure 1 AOD measurements from sun photometer for 2014

From this time series, the most continuous measurements are during summer time for which we made interpolated the missing values using a cubic function. The power spectrum of this series is presented in Figure 2 and shows the following characteristic periods: 20 days, 10 days, 5 days and some smaller components to 6.7 days, 2.9 and 2.4 days. These latter frequencies are most probably linked to urban aerosol due to weekly traffic variations [8]

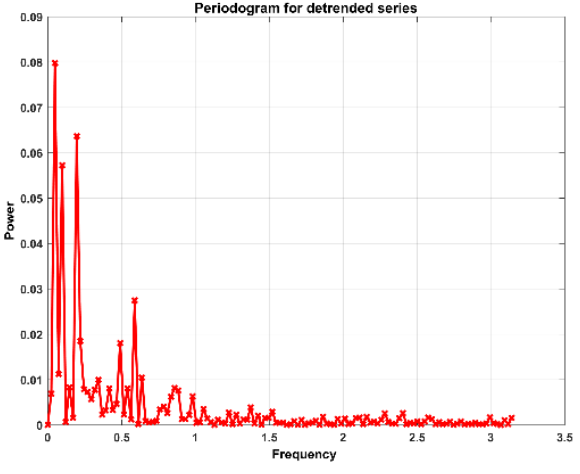

Figure 2 Periodogram for the AOD data

Eliminating the frequencies from the natural and anthropogenic influences we focused on one case (Figure 3)

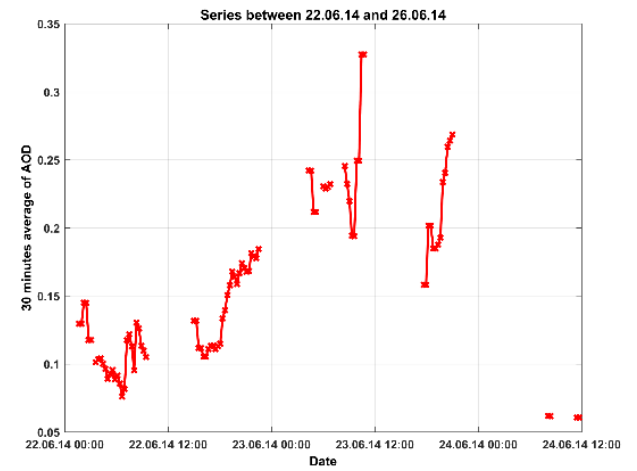

Figure 3 Case of 23.06 - 25.06 a half an hour mean data

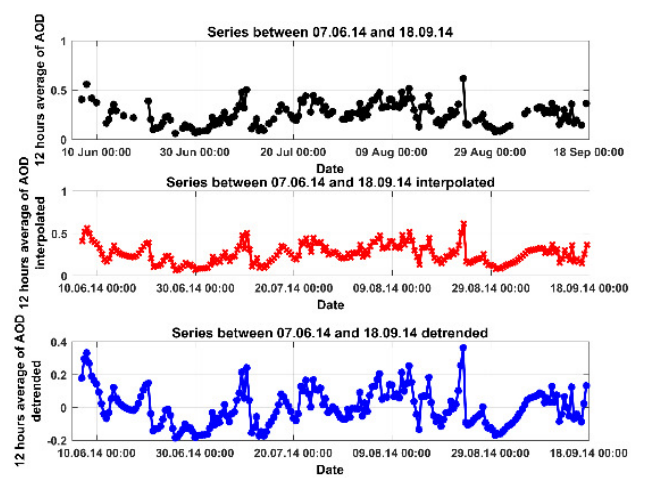

Figure 4 Series of AOD averaged for 12 hours (I), interpolated (II) and detrended (III)

In this case, range corrected signal quicklook (Figure 4) shows the planetary boundary layer in the lower region (between 0.5 and $1 \mathrm{~km}$ ) while in the free one can expect relatively higher values in 
the backscatter profile due to the presence of a diffuse aerosol layer..

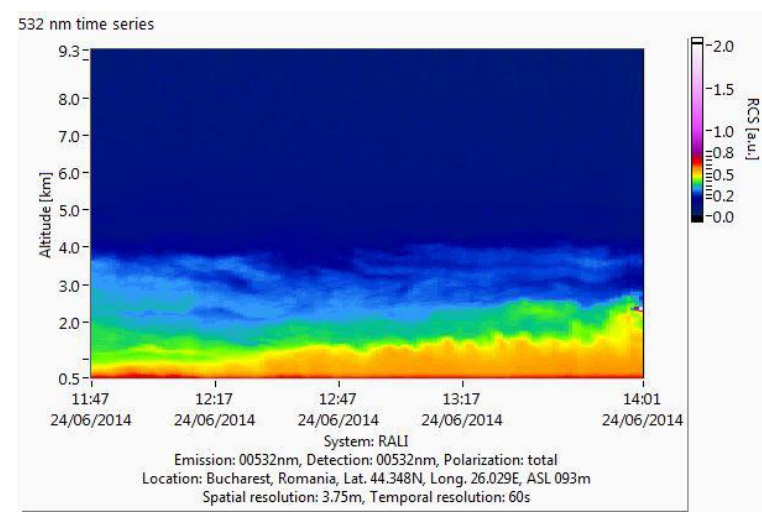

Figure 4 Range Corrected signal for 24th of June 2014

Visualization of the backscatter coefficient profiles at $532 \mathrm{~nm}$ channel from the ground based lidar system and Calipso can be seen in Figure 5. Both systems are in a good agreement showing higher values of backscatter coefficient in the $3 \mathrm{~km}-4 \mathrm{~km}$ region.

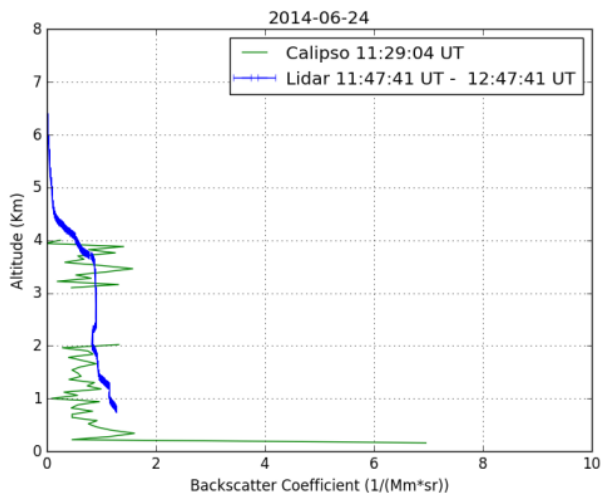

Figure 5 Backscatter coefficient from both Calipso and Lidar measurements from $24^{\text {th }}$ of June 2014

CAD score for the Calipso profiles show values between -97 and -100 which indicates the presence of aerosols with high confidence.

This region is due to long range transport aerosol layer and can be validated using the backwards trajectories from the HYSPLIT model which shows the source (Figure 6) for 2, 3 and $4 \mathrm{~km}$ altitudes sources.

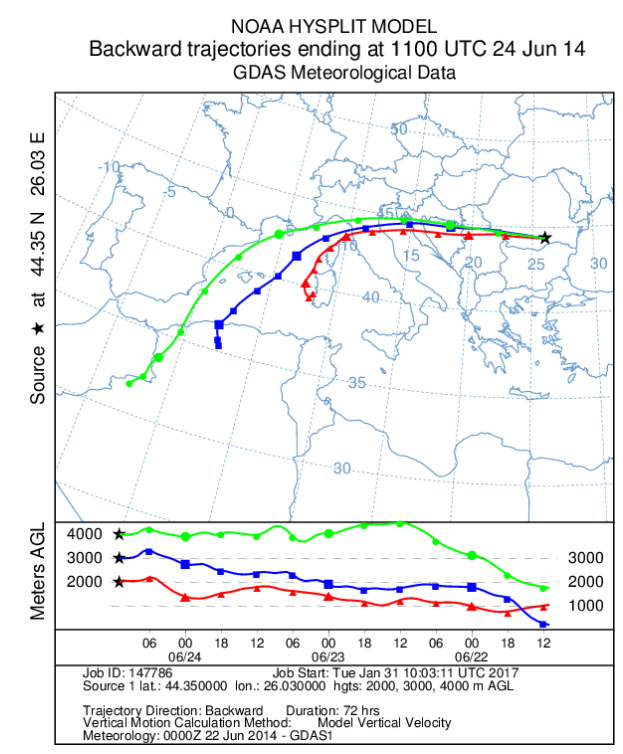

Figure 6 HYSPLIT backwards trajectories for 24.06.2014

AOD values obtained from the Lidar profile have a value of $0.1908 \pm 0.0003$ while from the Calipso extinction coefficient profile the values has a value of $0.1568 \pm 0.0629$. The AOD values obtained from the sun photometer in same time period shows a mean value of $0.2028 \pm 0.0026$ and a variability between 0.1848 and 0.2228 . As expected, the values are lower than both lidar systems, ground based and from Calipso because neither lidar systems have the information for all the atmospheric column [9].

Earlier that case, another range corrected signal quicklook (Figure 7) show similar atmospheric condition with a long range transporter aerosol layer which can be validated by running the backwards trajectories provided by HYSPLIT model (not shown).

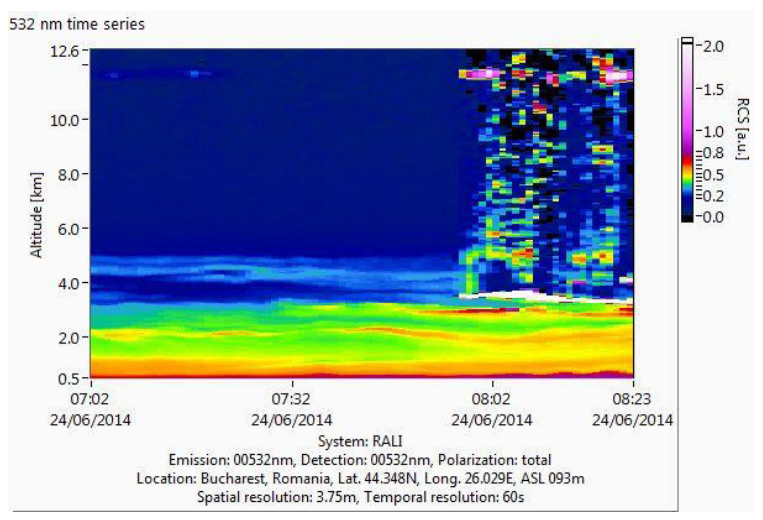

Figure 7 Range Corrected Signal from ground based lidar 
The aerosols shown in the $3 \mathrm{~km}$ region acted as cloud nuclei in the last time period of the measurement, the radiation from the lidar system being highly backscattered.

\section{CONCLUSIONS}

Using a high rate of sampling for AOD data measured in the summer of 2014, we identify long periods variations, 20 and 10 days driven by local climatic conditions and shorts periods of AOD variations $(5,2.9$ and 2.4days) due to induced air pollution and due to intense weekly traffic of Bucharest.

The irregularities shown in the AOD time series from sun photometer data can indicate extreme cases of long range transport of aerosol layer and clouds formation.

In the case presented in this paper, satellite data from Calipso and ground based Lidar measurements were used to validate not only the Planetary Boundary Layer height, but also the presence of long range transported aerosols.

Also, the values obtained for AOD from both Calipso and ground based lidar systems and sun photometer data are in a good agreement showing that the validation made with both lidar systems was a suitable one.

Earlier ground based lidar measurement of that case showed that the aerosol layer found acted as nuclei for cloud formation.

\section{ACKNOWLEDGEMENTS}

Satellite data were obtained from the NASA Langley Research Center Atmospheric Science Data Center.

This work has been supported by the European Union's Horizon 2020 Research and Innovation Programme, under the Grant Agreement no 692014 - ECARS, by the National Core ProgramPN16.40.01.01/2016, by ESA contract 4000113511/NL/FF/gp- AROMAT. Also this project has received funding from the European Union's Horizon 2020 research and innovation programme under grant agreement No 654109, ACTRIS 2.

\section{References}

[1] Xia, X., T. F. Eck, B. N. Holben, G. Phillippe, and H. Chen 2008, Analysis of the weekly cycle of aerosol optical depth using AERONET and MODIS data, J. Geophys. Res., 113, D14217, doi:10.1029/2007JD009604

[2] Dubovik, O. and M. D. King, 2000: A flexible inversion algorithm for retrieval of aerosol optical properties from Sun and sky radiance measurements," J. Geophys. Res., 105, 20 67320696

[3] Nemuc, A., Nicolae, D., Talianu, C., Carstea, E., Radu, C. (2009). Dynamic of the lower troposphere from multiwavelengthlidar measurements. Rom. Rep. Phys., 61, 313-323;

[4] Fernald, F.G., Herman, B. M., and Reagan, J. A. (1972). Determination of aerosol height distribution of Lidar J. Appl. Meteorol, 11, 482 - 489;

[5] Klett, J.D. 1981, Stable Analytical Inversion Solution for Processing Lidar Returns, Appl. Opt, 20, 211 - 220;

[6] Belegante, L., et al., 2004, Retrieval of the boundary layer height from active and passive remote sensors. Comparison with a NWP model,. ActaGeographica, 62, 2, 276 - 289;

[7] Dubovik, O., B. N. Holben, T. F. Eck, A. Smirnov, Y. J. Kaufman, M. D. King, D. Tanré, and I. Slutsker, "Variability of absorption and optical properties of key aerosol types observed in worldwide locations", J. Atmos. Sci.,59, 590-608, 2002 b.

[8] Dominique Ba"umer and Bernhard Vogel, 2007, An unexpected pattern of distinct weekly periodicities in climatologica lvariables in Germany, Geophysical Research Letters, vol. 34, L03819, doi:10.1029/2006GL028559

[9] A. Nemuc, I. Binietoglou, S. Andrei, A. Dandocsi, H. Stefanie, 2016, Multiyear aerosol study based on lidar \& sun photometer measurements in Romania, The European Physical Journal Conferences 119:24001, DOI: 10.1051/epjconf/201611924001 